\title{
Analysis of cell hyperplasia and parietal cell dysfunction induced by Ostertagia ostertagi infection
}

Belgacem Mihi ${ }^{1}$, Frederik Van Meulder ${ }^{1}$, Manuela Rinaldi ${ }^{1}$, Stefanie Van Coppernolle ${ }^{1}$, Koen Chiers ${ }^{2}$, Wim Van den Broeck ${ }^{3}$, Bruno Goddeeris ${ }^{1}$, Jozef Vercruysse ${ }^{1}$, Edwin Claerebout ${ }^{1}$ and Peter Geldhof ${ }^{1 *}$

\begin{abstract}
Infections in cattle with the gastric nematode Ostertagia ostertagi are associated with decreased acid secretion and profound physio-morphological changes of the gastric mucosa. The purpose of the current study was to investigate the mechanisms triggering these pathophysiological changes. O. ostertagi infection resulted in a marked cellular hyperplasia, which can be explained by increased transcriptional levels of signaling molecules related to the homeostasis of gastric epithelial cells such as HES1, WNT5A, FGF10, HB-EGF, AREG, ADAM10 and ADAM17. Intriguingly, histological analysis indicated that the rapid rise in the gastric $\mathrm{pH}$, observed following the emergence of adult worms, cannot be explained by a loss of parietal cells, as a decrease in the number of parietal cells was only observed following a long term infection of several weeks, but is likely to be caused by an inhibition of parietal cell activity. To investigate whether this inhibition is caused by a direct effect of the parasites, parietal cells were co-cultured with parasite Excretory/Secretory products (ESP) and subsequently analyzed for acid production. The results indicate that adult ESP inhibited acid secretion, whereas ESP from the L4 larval stages did not alter parietal cell function. In addition, our data show that the inhibition of parietal cell activity could be mediated by a marked upregulation of inflammatory factors, which are partly induced by adult ESP in abomasal epithelial cells. In conclusion, this study shows that the emergence of adult O. ostertagi worms is associated with marked cellular changes that can be partly triggered by the worm's Excretory/secretory antigens.
\end{abstract}

\section{Introduction}

Infections with the abomasal nematode Ostertagia ostertagi are considered as a major source of economic losses in cattle throughout the temperate regions of the world. O. ostertagi infection results in profound physio-morphological and functional alterations of gastric mucosal cells [1]. The gastric fundic mucosa is organized in well-defined units referred to as gastric glands composed by different cell lineages [2]. Homeostasis of this highly renewing epithelium is under a tight regulation of different molecular and cellular signaling pathways that keep a balance between proliferation and differentiation of the different gastric cell populations. Changes in the mucosal microenvironment induced by gastric infections lead to the disturbance of gastric cell

\footnotetext{
* Correspondence: peter.geldhof@ugent.be

${ }^{1}$ Department of Virology, Parasitology and Immunology, Faculty of Veterinary Medicine, Ghent University, Salisburylaan 133, 9820 Merelbeke, Belgium Full list of author information is available at the end of the article
}

homeostasis [3]. Abomasal ostertagiosis is characterized by mucous cell hyperplasia, impairment of parietal cell function and the replacement of functional parietal cells by an undifferentiated cell population [1,4]. The molecular mechanisms mediating these mucosal changes during an $O$. ostertagi infection remain largely unknown. Minor cellular changes are first confined around the nodules containing the immature larvae. After the emergence of adult worms from the gastric glands, the changes tend to become more general $[5,6]$. Huby et al. showed that the excretory/ secretory products (ESP) of ruminant gastrointestinal nematodes could increase the proliferation of gastric cell lines [7]. In addition, Simpson et al. showed that the transplantation of T. circumcincta adult worms, confined in porous bags, lead to a significant increase of abomasal $\mathrm{pH}$ and serum gastrin within a few hours. Altogether, these data suggest a key role of ESP in the pathobiology of abomasal nematode infections [8]. Previous data showed that similar

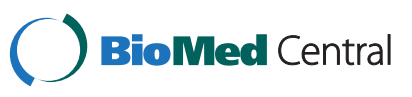


changes occur in response to bacterial, viral, and parasitic infections, suggesting the existence of a conserved host response [9-12]. It has been shown that these mucosal changes can be triggered by a local inflammatory response, as increased expression levels of pro-inflammatory factors such as IL1B, TNFA and prostaglandin E2 (PGE2) are associated with the impairment of parietal cell function and the alterations of mucosal cell homeostasis [13-16]. In addition to inflammatory factors, changes in expression levels of SHH (Sonic Hedgehog), FGF (Fibroblast Growth Factors), BMP (Bone Morphogenetic proteins), WNT (WinglessType) and NOTCH could induce an imbalance between cell proliferation and cell differentiation in the gastric mucosa [3]. The role played by all these factors in the pathogenesis of abomasal ostertagiosis is still unknown.

Therefore, in order to improve our understanding of the pathobiology of cattle ostertagiosis, the purpose of the current study was to investigate the pathophysiological alterations affecting mucosal cells and to unravel the changes in the signaling pathways that might generate these alterations. Finally, we also wanted to analyze whether the inhibition of parietal cell activity is triggered by a direct effect of $O$. ostertagi ESP and/or by increased levels of inflammatory factors.

\section{Materials and methods}

\section{Infection trials, tissue collection and parasite material}

The experimental design was described previously by Mihi et al. [17]. Briefly, nematode-free Holstein calves, aged 6 to 8 months, were randomly assigned into the different experimental groups. Three groups of four calves were orally infected with a single dose of 100000 O. ostertagi L3 larvae/animal and killed after 6, 9 and 24 days post infection (dpi), respectively, corresponding to the presence of L3, L4 and adult stages. Another group of four calves was maintained uninfected and used as a negative control. For histological analysis, an additional group of three calves was infected with the same challenge and killed at 21 dpi. Furthermore, a group of four calves was maintained on a pasture to acquire a natural $O$. ostertagi infection and euthanized 60 days after the first exposure (60 days post exposure (dpe)). An additional group has been included in this study, in which six calves received 1000 L3 infective larvae per day during 30 days and were killed 60 days after the first challenge (60 dpi). The experimental protocol was carried out with the approval from the ethical committee of the Faculty of Veterinary Medicine at Ghent University. Parasite collection, culture and ESP purification were performed as previously described by Geldhof et al. [18]. The postmortem worm counts were performed according to the method described by Geldhof et al. [19]. LPS contamination of worms ESP was quantified using ToxinSensor TM chromogenic LAL endotoxin assay kit (GenScript) according to the manufacturer's instructions.

\section{Cell culture}

Bovine mucous epithelial cell culture was carried out following the method described by Hoorens et al. [20]. Isolation and culture of parietal cells was performed as previously described with some modifications [21]. In short, rabbit and bovine stomachs collected from slaughterhouses were washed and transported in cold PBS. The stomachs were inspected for the presence of inflammation or signs of infection. The mucus was removed using a glass slide and the mucosa was scraped off and minced in very small fragments. After successive washing steps with PBS and MEM (Invitrogen), the minced mucosa was digested for $30 \mathrm{~min}$ in MEM medium supplemented with $2 \mathrm{mg} / \mathrm{mL}$ collagenase Type 1 (Invitrogen) and $5 \mathrm{mg} / \mathrm{mL}$ BSA. The digestion was stopped by three-fold dilution of the collagenase solution and big undigested fragments were removed using a 220 $\mu \mathrm{m}$ mesh sieve. The gastric glands were allowed to settle down for 20 min after which the supernatant was discarded and the remaining glands were further dissociated mechanically by pipetting the solution up and down. The cells were washed and centrifuged three times at $350 \mathrm{~g}$ for $5 \mathrm{~min}$. The resulting cells were filtrated through $40 \mu \mathrm{m}$ cell strainers, washed three times in PBS and incubated in medium A containing: DMEM/F12 (Sigma Aldrich) supplemented with $20 \mathrm{mM}$ Hepes, 0.2\% BSA, $10 \mathrm{mM}$ glucose, 8 nM EGF (Sigma Aldrich), $1 \times$ Insulin, Transferrin, Selenium Solution (ITS -G) (Gibco), 1\% penicillin-streptomycin, $50 \mathrm{mg} / \mathrm{mL}$ amphotericin B and $25 \mu \mathrm{g} / \mathrm{mL}$ gentamycin (Invitrogen). The cells were washed in PBS and plated on chambered coverslips (Nunc) coated with Matrigel basement membrane (BD bioscience) diluted at $1 / 7$ in ice-cold sterile water and incubated at $37^{\circ} \mathrm{C}$ in medium $\mathrm{A}$ without amphotericin B.

\section{RNA extraction and cDNA synthesis}

Total RNA was extracted from tissue samples using Trizol (Invitrogen) and further purified using the RNeasy Mini kit (Qiagen), while total RNA was extracted from cultured cells using the RNeasy Mini Kit (Qiagen) without previous Trizol treatment. Removal of contaminating genomic DNA was performed using DNase set (Qiagen) according to the manufacturer's instructions. RNA quality was verified using an Experion ${ }^{\mathrm{TM}}$ Automated Electrophoresis System (Bio-Rad) and the concentrations were determined using a NanoDrop ND-1000 spectrophotometer (NanoDrop Technologies). Total RNA was converted into cDNA using the iScript cDNA synthesis kit (Bio-Rad), according to the manufacturer's instructions.

\section{Quantitative Real-time PCR}

Real time PCR reactions were carried out as described elsewhere [17]. Primer sequences are shown in Additional file 1. Amplification cycles were performed on a StepOnePlus Real-Time PCR System (Applied Biosystems) under 
the following conditions: $95^{\circ} \mathrm{C}$ for $20 \mathrm{~s}$ followed by 35 cycles of $95^{\circ} \mathrm{C}$ for $15 \mathrm{~s}$, primer's melting temperature (Additional file 1) for $15 \mathrm{~s}$, and $72{ }^{\circ} \mathrm{C}$ for $15 \mathrm{~s}$. A melting curve analysis was performed at the end of the reaction to ensure the specificity of the primers. The quantification of gene expression was carried out using the delta-delta CT method in cell culture experiments. The quantification of gene expression at the mucosal level following $O$. ostertagi infection was obtained by transforming the $\mathrm{Ct}$ values into relative quantities [17]. Gene expression was evaluated based on fold differences in gene transcription levels at different time points during the infection compared to the negative control animals. This was done by calculating the ratios of individual relative quantities on the geometric means of relative values of the control samples.

\section{Histology and immunofluorescence}

For immunofluorescence, $5 \mu \mathrm{m}$ formaldehyde-fixed tissue sections were successively deparaffinized in xylene, rehydrated in graded ethanol and rinsed in PBS. Sections were boiled in Antigen Retrieval Citra Microwave Solution and washed respectively $15 \mathrm{~min}$ in water and $5 \mathrm{~min}$ in PBS. Sections were permeabilized in $2 \%$ bovine serum albumin (BSA), $0.3 \%$ TritonX-100 PBS for $15 \mathrm{~min}$, then blocked in $2 \%$ BSA in PBS for 45 min. Tissue sections were incubated with primary antibodies diluted 100 times (rabbit antiATP4A IgG (Calibiochem), rabbit anti-Ki-67 IgG (Abcam)) overnight at $4{ }^{\circ} \mathrm{C}$. After washing with PBS, tissue specimens were incubated for $1 \mathrm{~h}$ with a secondary antibody diluted 100 times (Alexa Fluor 488 goat anti-rabbit IgG (Invitrogen)). DAPI $(1.5 \mu \mathrm{g} / \mathrm{mL})$ was used to counterstain the nuclei. Tissue sections were rehydrated in an ethanol gradient and were mounted in DEPX mounting medium (VWR). The slides were observed using a LEICA microscope. In order to count parietal cells, four random pictures were chosen from each stained section. Parietal cell count was performed using one ATP4A stained section per animal. Positive ATP4A stained cells were counted in a $200 \mu \mathrm{m}$ wide area from the bottom of the glands to the mucosal surface using Image J software. The ATP4A staining of cultured parietal cells was carried out as described by Agnew et al. [21].

\section{Measurement of acid secretion}

The method applied to measure acid secretion by parietal cells has been described previously by Mangeat et al. [22]. Briefly, parietal cells grown on Matrigel coated Lab-TeK chambered coverslips were preincubated during $15 \mathrm{~min}$ or $24 \mathrm{~h}$ with or without $O$. ostertagi ESP and/or with different secretagogues for $20 \mathrm{~min}$. Parietal cells were then incubated for $10 \mathrm{~min}$ with $10^{-6} \mathrm{M}$ of 9-aminoacridine (9-AA) (Excitation: $400 \mathrm{~nm}$ - Emission $450 \mathrm{~nm}$ ). Cells were washed three times and perfused again with the same concentrations of ESP and/or secretagogue as used before. Ten random pictures were taken below the saturation levels of the 9AA fluorescence. The fluorescence intensity and the area of 9-AA within the secretory vacuoles were quantified using Image J software. The mean fluorescence intensity and the area of fluorescent vacuoles were measured in the blue channel after subtraction of background fluorescence. The multiplication product of the mean fluorescence intensity and the area of acidic vacuoles were representative of acid secretion index per parietal cell.

\section{Statistical analysis}

Statistical analysis was performed using GraphPad Prism software. For the infection trials, the data were analyzed using the Nonparametric Mann Whitney U test, by comparing the infected groups with the uninfected control. In cell culture experiments the analysis was carried out using the unpaired Student's $t$-test by comparing each group of treated cells with the PBS control group. A Pvalue of $\leq 0.05$ was considered as statistically significant.

\section{Results}

\section{Postmortem worm counts}

Postmortem worm counts (Additional file 2) showed that both natural and experimental $O$. ostertagi infections were successfully established. The numbers of worms recovered from naturally infected animals were substantially higher compared to the experimentally infected groups.

\section{Impact of O. ostertagi infection on mucosal cell proliferation}

In order to determine the impact of an O. ostertagi infection on mucosal cell proliferation, tissue sections were stained for Ki-67 as a cell proliferation marker (Figure 1). A marked increase of stained nuclei located in the neck zone of all the gastric glands was observed following both single or trickle infection. One animal from the 21 dpi group only showed proliferation in areas surrounding the glands containing the larvae and did not show a significant increase of stained nuclei in non-invaded mucosa (data not shown).

To determine which pathways are involved in the observed cellular hyperplasia and cell dedifferentiation, transcriptional changes of signaling molecules related to the homeostasis of gastric epithelial cells were investigated and the results are shown in Table 1. WNT5A, HES1, AREG, HB-EGF and FGF10 mRNA levels were increased in all infected groups. $A D A M 17$ and $A D A M 10$, two activators of several signaling molecules such as $H B-E G F$, were also significantly upregulated during both single and trickle infections. The highest increase observed for the impacted genes in single experimental infections was observed at $24 \mathrm{dpi}$. 

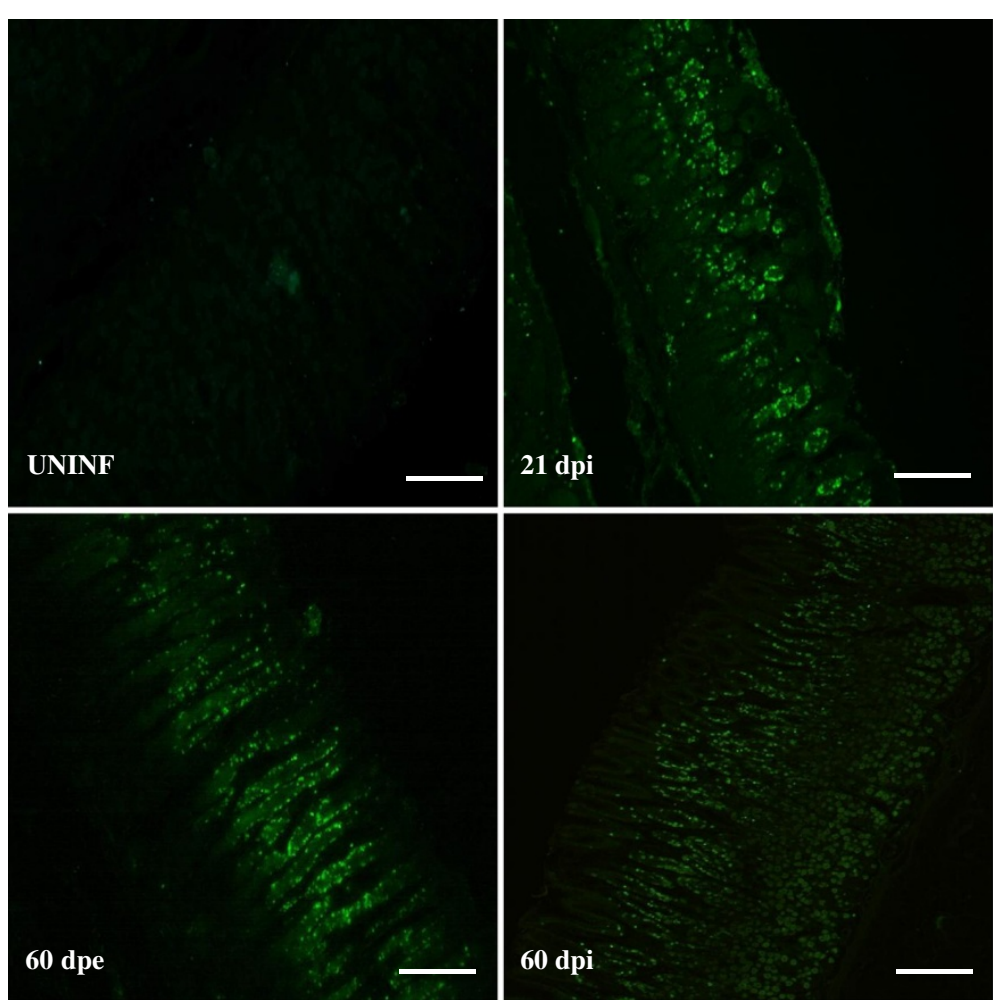

Figure 1 Representative pictures of fundic sections stained for the proliferation marker Ki67. Proliferative nuclei are stained in green. UNINF: uninfected, dpi: days post infection, dpe: days post exposure (Scale bar $=100 \mu \mathrm{m}$ ).

Effect of O. ostertagi infection on parietal cells and their activation

It was shown previously that following O. ostertagi infection, there is an inhibition of gastric acid secretion [4]. In order to unravel the mechanism behind this inhibition, parietal cells were stained with ATP4A antibody and subsequently counted in the abomasal mucosa following an $O$. ostertagi infection. Although the total parietal cell number was unchanged at $21 \mathrm{dpi}(128.33 \pm 9.27)$ compared to the uninfected control animals $(122.81 \pm 5.5)$, a focal loss of

Table 1 Effect of an 0 . ostertagi on transcript levels of signaling network components involved in gastric cell homeostasis (mean fold difference compared to uninfected calves \pm SEM)

\begin{tabular}{|c|c|c|c|c|c|}
\hline \multirow[b]{3}{*}{ Gene } & \multicolumn{3}{|c|}{ Single infection } & \multicolumn{2}{|c|}{ Trickle infection } \\
\hline & & Experimenta & & \multirow{2}{*}{$\begin{array}{l}\text { Experimental } \\
60 \mathrm{dpi}\end{array}$} & \multirow{2}{*}{$\begin{array}{l}\text { Natural } \\
60 \text { dpe }\end{array}$} \\
\hline & $6 \mathrm{dpi}$ & 9 dpi & 24 dpi & & \\
\hline HB-EGF & $2.61 \pm 1.3$ & $4.47 \pm 0.68^{*}$ & $7.12 \pm 1.33^{*}$ & $6.45 \pm 1.11^{* *}$ & $5.13 \pm 1.31^{*}$ \\
\hline AREG & $3.57 \pm 1.78^{*}$ & $4.01 \pm 0.82^{*}$ & $11.40 \pm 1.58^{*}$ & $7.79 \pm 0.77^{* *}$ & $8.86 \pm 2.48^{*}$ \\
\hline FGF10 & $2 \pm 0.2$ & $2.34 \pm 0.43$ & $4.33 \pm 0.45^{*}$ & $1.83 \pm 0.13^{* *}$ & $2.58 \pm 0.46^{*}$ \\
\hline HES1 & $1.79 \pm 0.24^{*}$ & $2.07 \pm 0.34^{*}$ & $2.3 \pm 0.3^{*}$ & $3.20 \pm 0.36^{* *}$ & $1.97 \pm 0.2^{*}$ \\
\hline ADAM10 & $1.66 \pm 0.83^{*}$ & $2.44 \pm 0.6^{*}$ & $2.64 \pm 0.68^{*}$ & $1.76 \pm 0.19$ & $2.14 \pm 0.22^{*}$ \\
\hline ADAM17 & $1.96 \pm 0.25^{*}$ & $2.16 \pm 0.29^{*}$ & $3.5 \pm 0.6^{*}$ & $2.41 \pm 0.25^{* *}$ & $2.66 \pm 0.26^{*}$ \\
\hline Wnt5A & $1.93 \pm 0.17^{*}$ & $1.92 \pm 0.31^{*}$ & $3.09 \pm 0.22^{*}$ & $2.76 \pm 0.30^{* *}$ & $2.01 \pm 0.31^{*}$ \\
\hline $\mathrm{SHH}$ & $2.25 \pm 0.68$ & $2.26 \pm 1.06$ & $1.98 \pm 0.49$ & $2.93 \pm 0.61^{* *}$ & $1.81 \pm 0.44$ \\
\hline BMP4 & $1.31 \pm 0.16$ & $1.7 \pm 0.36$ & $1.63 \pm 0.14$ & $1.69 \pm 0.15$ & $1.26 \pm 0.09$ \\
\hline FGF20 & $2.27 \pm 0.33$ & $2.87 \pm 1.78$ & $1.95 \pm 0.31$ & $1.44 \pm 0.26$ & $2.94 \pm 0.31^{*}$ \\
\hline GIF & $1.7 \pm 0.22$ & $1.13 \pm 0.05$ & $0.85 \pm 0.15$ & $0.61 \pm 0.01^{* *}$ & $0.72 \pm 0.15$ \\
\hline
\end{tabular}

${ }^{*} p$ value $\leq 0.05$ uninfected animals vs infected animals.

${ }^{* *} p$ value $\leq 0.01$ uninfected animals vs infected animals. 
parietal cells was consistently observed around gastric cysts, containing an immature larva. A significant diffused decrease of parietal cells was observed after both experimental and natural trickle infections $(94.5 \pm 4.27$ and $62.31 \pm 14.52)$ (Figure 2). In addition to the immunofluorescent staining, the transcriptional analysis of parietal cell markers shows that $A T P 4 A$ and $A Q P 4$ were significantly down regulated following a trickle infection, whereas $K C N Q 1$ transcript levels were unchanged in all animals (Table 2). All together, these data show that parietal cell loss occurs following a long period of parasite exposure.

In order to understand how an O. ostertagi infection results in inhibition of gastric acid secretion upon the emergence of adult worms, in the absence of parietal cell loss, transcriptional levels of different genes involved in the endocrine activation process of parietal cells were assessed. The expression levels of the cholecystokinin $\mathrm{B}$ receptor $(C C K B R)$ and histidine decarboxylase $(H D C)$, which are implicated in histamine production by enterochromaffin like cells, were not impacted by the infection. Furthermore, the expression of the histamine receptor $\mathrm{HRH2}$, which is responsible for parietal cell activation, was not affected by the infection, except on $6 \mathrm{dpi}$ where a small increase was observed (Table 2).

\section{Impact of 0 . ostertagi ESP on parietal cell activity}

In an attempt to study the inhibitory activity of $O$. ostertagi ESP on the acid secretion of parietal cells, bovine parietal cells were first isolated and cultured. The proportion of attached bovine parietal cells obtained after 16 hours of culture was less than $5 \%$. After 48 h, only a few bovine parietal cells were still attached to the coverslips. Under histamine and carbachol stimulation, bovine parietal cells did not show any reorganization of ATP4B location (Figure 3). These data suggest that the cultured bovine parietal cells were not responsive to the common secretagogues. In contrast, the same protocol applied on rabbit parietal cells resulted in $70 \%$ of attached parietal cells after being placed in culture for $16 \mathrm{~h}$. In resting state, ATP4B staining was diffused in the cytoplasmic compartment, whereas under histamine and carbachol stimulation, ATP4B was translocated along secretory vacuoles (Figure 3). Therefore, the impact of O. ostertagi ESP on acid secretion was further investigated using cultured rabbit parietal cells.

Cultured rabbit parietal cells were incubated for $24 \mathrm{~h}$ with different concentrations of adult or L4 ESP material. None of the L4 ESP concentrations showed any effect on histamine and carbachol stimulation (Figure 4A), whereas incubation of parietal cells with $100 \mu \mathrm{g} / \mathrm{mL}$ of adult ESP
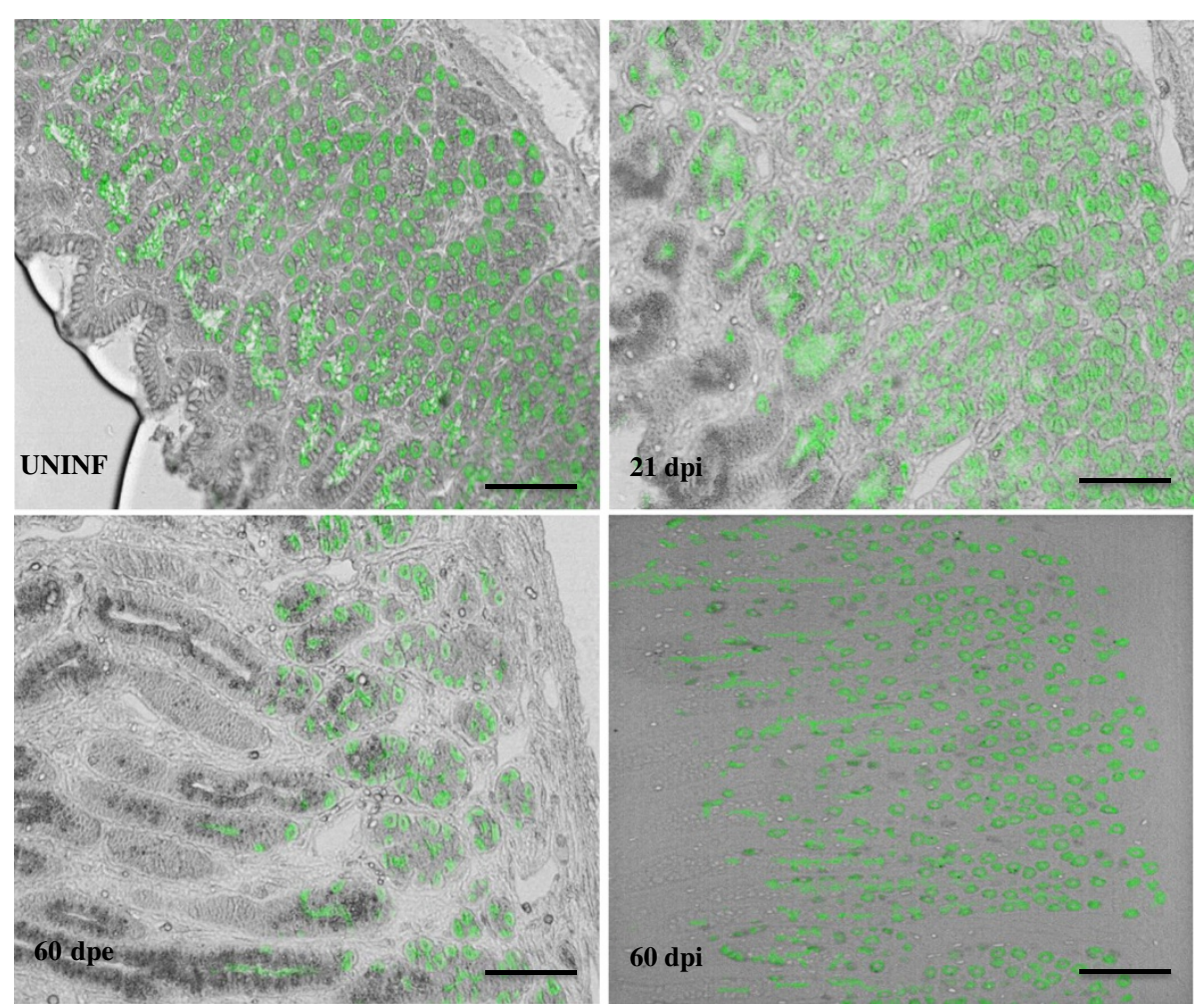

Figure 2 Impact of an O.ostertagi infection on parietal cell numbers. Parietal cells are visualized in fundic sections by immunostaining for ATP4A. Parietal cells are stained in green. UNINF: uninfected, dpi: days post infection, dpe: days post exposure (Scale bar $=100 \mu \mathrm{m}$ ). 
Table 2 Effect of an O. ostertagi on transcript levels of physiologic gastric acid secretion regulators (Mean fold difference compared to uninfected calves \pm SEM)

\begin{tabular}{|c|c|c|c|c|c|}
\hline \multirow[b]{3}{*}{ Gene } & \multicolumn{3}{|c|}{ Single infection } & \multicolumn{2}{|c|}{ Trickle infection } \\
\hline & & xperimental & & \multirow{2}{*}{$\begin{array}{l}\text { Experimental } \\
60 \mathrm{dpi}\end{array}$} & \multirow{2}{*}{$\begin{array}{l}\text { Natural } \\
60 \text { dpe }\end{array}$} \\
\hline & $6 \mathrm{dpi}$ & $9 \mathrm{dpi}$ & $24 \mathrm{dpi}$ & & \\
\hline ATP4A & $1.62 \pm 0.35$ & $0.75 \pm 0.08$ & $0.49 \pm 0.14$ & $0.67 \pm 0.04$ & $0.29 \pm 0.05^{*}$ \\
\hline AQP4 & $1.05 \pm 0.53$ & $0.99 \pm 0.25$ & $0.88 \pm 0.08$ & $0.64 \pm 0.02^{* *}$ & $0.42 \pm 0.06^{*}$ \\
\hline KCNQ1 & $1.56 \pm 0.17$ & $1.11 \pm 0.18$ & $1.42 \pm 0.24$ & $1.27 \pm 0.04$ & $1.6 \pm 0.25$ \\
\hline HDC & $1.57 \pm 0.07^{*}$ & $1.33 \pm 0.17$ & $1.83 \pm 0.4$ & $0.94 \pm 0.05$ & $1.53 \pm 0.37$ \\
\hline $\mathrm{H} 2 \mathrm{HR}$ & $2.18 \pm 0.23^{*}$ & $1.1 \pm 0.24$ & $1.34 \pm 0.21$ & $0.92 \pm 0.09$ & $0.69 \pm 0.08$ \\
\hline CCKBR & $0.95 \pm 0.22$ & $1.39 \pm 0.35$ & $0.59 \pm 0.15$ & $0.70 \pm 0.5^{*}$ & $0.72 \pm 0.1$ \\
\hline
\end{tabular}

${ }^{*} p$ value $\leq 0.05$ uninfected animals vs infected animals.

${ }^{* *} p$ value $\leq 0.01$ uninfected animals vs infected animals.

significantly inhibited the 9-AA accumulation by $53 \%$. In contrast, no inhibitory effect was seen using the same concentration of adult ESP on carbachol stimulated cells. Furthermore, incubation of parietal cells with $100 \mu \mathrm{g} / \mathrm{mL}$ of adult worm protein extract or boiled adult worm ESP did not affect acid secretion (Figure 4B). In contrast with the $24 \mathrm{~h}$ pre-incubation period, $15 \mathrm{~min}$ pre-incubation of parietal cells with adult ESP at $100 \mu \mathrm{g} / \mathrm{mL}$ did not significantly alter the histamine induced acid secretion (Figure 4C). In order to investigate the impact of adult ESP on histamine receptor independent activation of acid secretion, parietal cells were stimulated with dbcAMP following $24 \mathrm{~h}$ of incubation with adult ESP. Adult ESP significantly reduced dbcAMP stimulation of acid secretion (Figure 4D).

\section{Mucosal inflammatory response induced by 0 . ostertagi} Previous studies showed that inflammatory factors could be involved in the impairment of gastric epithelial cell homeostasis and parietal cell function. Therefore, transcriptional changes of inflammatory related-genes were investigated in the abomasal mucosa following an O. ostertagi infection and the results are shown in Table 3. The inflammatory factors $I L 1 B, I L 8$ and $C O X-2$ exhibited increased transcriptional levels in the animals infected with a single dose of $O$. ostertagi compared to the uninfected group. In contrast, TNFA mRNA levels were not affected by the infection. The most important transcriptional changes following a single experimental infection occurred at 24 dpi. In addition, transcriptional analysis of inflammatory factors in animals receiving a trickle infection for a long period of time, shows that $I L-8$ was significantly upregulated at 60 dpe and $60 \mathrm{dpi}$, whereas COX-2, IL1B and TNFA were only significantly upregulated in the $60 \mathrm{dpi}$ group.

In order to investigate whether O. ostertagi ESP are implicated in the induction of these inflammatory factors, expression levels of ILIB, COX-2, IL8 and TNFA were

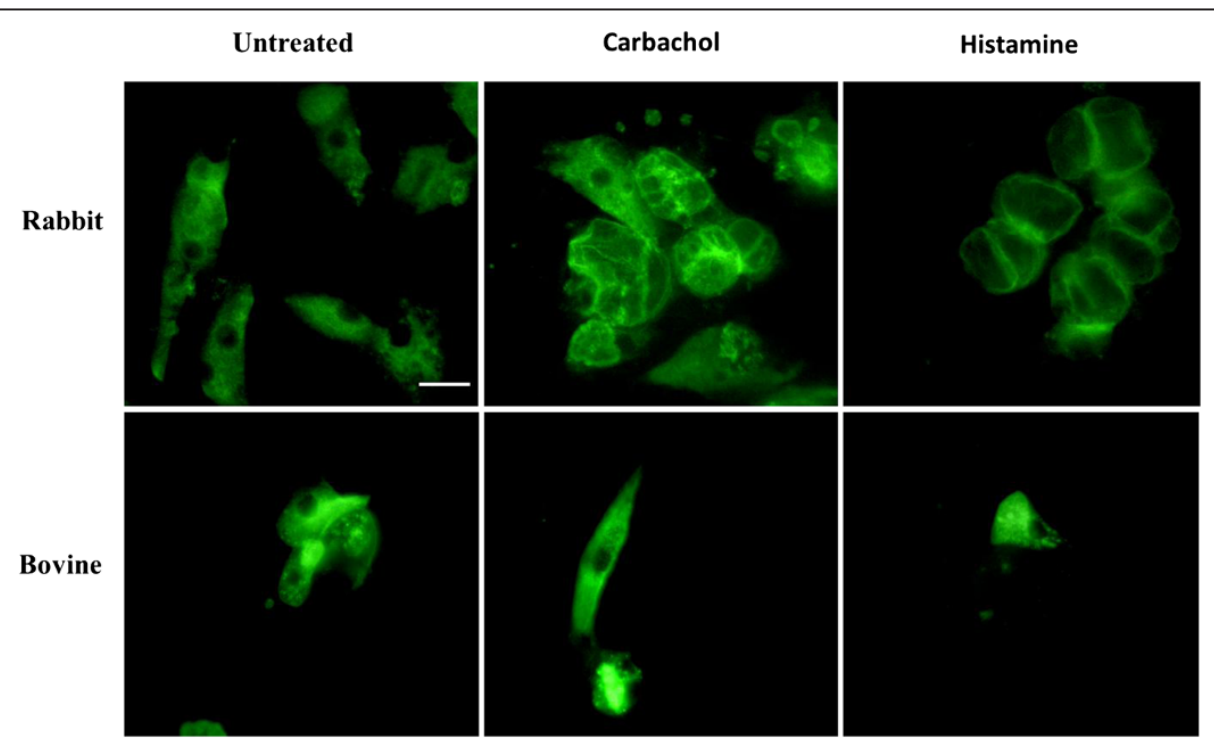

Figure 3 Effect of histamine and carbachol treatment on ATP4A cytoplasmic distribution in cultured rabbit and bovine parietal cells. Parietal cells were treated with histamine (10-5 M), carbachol (10-5 M) or PBS for 30 minutes prior to ATP4A staining. (Scale bar = $10 \mu \mathrm{m}$ ). 

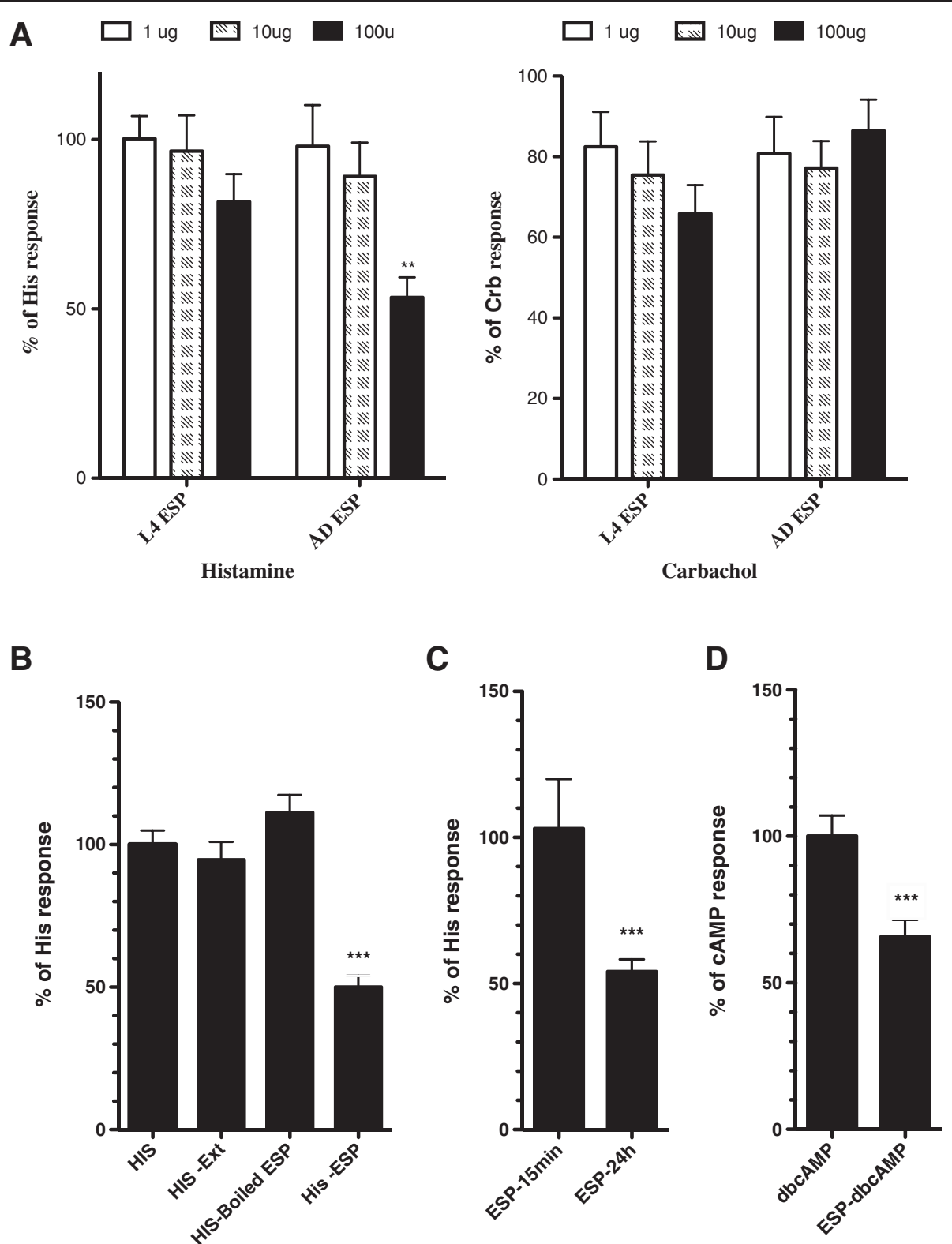

Figure 4 Impact of $\boldsymbol{O}$. ostertagi ESP on parietal cell activity. (A) Cultured rabbit parietal cells were pre-incubated with parasite ESP at different concentrations for $24 \mathrm{~h}$, and then stimulated with histamine (10-5 M) or carbachol (10-5 M) for 15 min. Quantitation of acid-secretion was measured using 9-aminoacridine accumulation as described in the material and methods. Data are expressed as percentages (means \pm SEM) of secretory index in histamine or carbachol stimulated parietal cells in the absence of ESP treatment. (B) Quantification of acid secretion in histamine stimulated rabbit parietal cells following $24 \mathrm{~h}$ of pre-incubation with native adult extract, adult ESP and boiled ESP at $100 \mu \mathrm{g} / \mathrm{mL}$ (C) Quantification of acid secretion following $15 \mathrm{~min}$ and $24 \mathrm{~h}$ of incubation with adult ESP. (D) Quantification of acid secretion in dbcAMP stimulated rabbit parietal cells following $24 \mathrm{~h}$ of preincubation with $100 \mu \mathrm{g} / \mathrm{mL}$ adult ESP. Data are expressed as percentages (means \pm SEM) of secretory index in dbcAMP or carbachol stimulated parietal cells in the absence of ESP treatment. (** $p$ value $\leq 0.01,{ }^{* *} p$ value $\leq 0.001$ ).

measured in cultured bovine mucous cells treated with L4 and adult ESP for $24 \mathrm{~h}$ (Figure 5). Expression levels of TNFA, COX-2, IL1B and IL8 were not impacted by L4 ESP treatment. In contrast, $I L 1 B$ and $C O X-2$ mRNA levels were significantly higher in the cells treated with $25 \mathrm{ug} / \mathrm{mL}$ adult ESP, while TNFA and IL8 transcriptional levels were unchanged by the same concentration compared to the PBS control.

\section{Discussion}

In agreement with previous reports, our data show that $O$. ostertagi infection results in marked mucosal alterations 
Table 3 Effect of an O. ostertagi on transcript levels of inflammatory-related genes (Mean fold difference compared to uninfected calves \pm SEM)

\begin{tabular}{|c|c|c|c|c|c|}
\hline \multirow[b]{3}{*}{ Gene } & \multicolumn{3}{|c|}{ Single infection } & \multicolumn{2}{|c|}{ Trickle infection } \\
\hline & & Experiment & & \multirow{2}{*}{$\begin{array}{c}\text { Experimental } \\
60 \mathrm{dpi}\end{array}$} & \multirow{2}{*}{$\begin{array}{l}\text { Natural } \\
60 \text { dpe }\end{array}$} \\
\hline & $6 \mathrm{dpi}$ & $9 \mathrm{dpi}$ & $24 \mathrm{dpi}$ & & \\
\hline IL1B & $3.01 \pm 1.29$ & $5.96 \pm 0.84^{*}$ & $35.37 \pm 10.77^{*}$ & $3.52 \pm 0.49^{*}$ & $5.51 \pm 1.86$ \\
\hline IL8 & $3.11 \pm 1.8$ & $5.52 \pm 1.6^{*}$ & $50.68 \pm 14^{*}$ & $8.53 \pm 1.55^{* *}$ & $9.65 \pm 2.66^{*}$ \\
\hline TNFA & $1.81 \pm 0.41$ & $2.02 \pm 0.31$ & $5.44 \pm 1.32$ & $2.20 \pm 0.0381^{*}$ & $3.76 \pm 1.06$ \\
\hline COX-2 & $1.05 \pm 0.1$ & $1.65 \pm 0.2$ & $6.45 \pm 1.67^{*}$ & $2.92 \pm 0.36^{* *}$ & $1.69 \pm 0.22$ \\
\hline
\end{tabular}

${ }^{*} p$ value $\leq 0.05$ uninfected animals vs infected animals.

${ }^{* *} p$ value $\leq 0.01$ uninfected animals vs infected animals.

affecting gastric epithelial cells. These changes are mainly associated with the development and appearance of adult worms in the abomasum.

Our data show that $O$. ostertagi infection triggers a prominent mucous cell hyperplasia in the neck zone of the fundic mucosa. Our data also show that the abomasal hyperplasia is associated with enhanced transcriptional levels of HES1, WNT5A and FGF10. These signaling molecules have been shown to play an important role in the maintenance of stem cell proliferation in the gastric isthmus [3]. It has been shown that the activation of WNT signaling in the gastric mucosa leads to an expansion of undifferentiated stem cells [23]. In addition, overexpression of FGF10 in chicken embryos leads to increased levels of BrdU incorporation in the stomach, attesting to the presence of glandular cell proliferation [24]. Furthermore, it has been shown that
HES1 is present in proliferating cells within the isthmus of gastric glands [25]. The overexpression of $B H L H$, a repressor of HES1, leads to an excessive endocrinal cell differentiation in the developing stomach, suggesting that HES1 plays a negative role on cell differentiation [26]. IL8, HB-EGF, AREG, ADAM10 and ADAM 17, which were all upregulated during $O$. ostertagi infection, may also have a trophic effect on abomasal epithelial cells. Joh et al. proposed a model where the activation of ADAM by IL8 can result in the cleavage of the HB-EGF precursor and the generation of an HB-EGF ligand, which in turn can induce epithelial cell proliferation [27].

It is also tempting to correlate the hyperplastic changes induced by $O$. ostertagi with the increased levels of inflammatory factors. It has been shown that IL1B stimulates gastric cell proliferation in vitro [28,29].

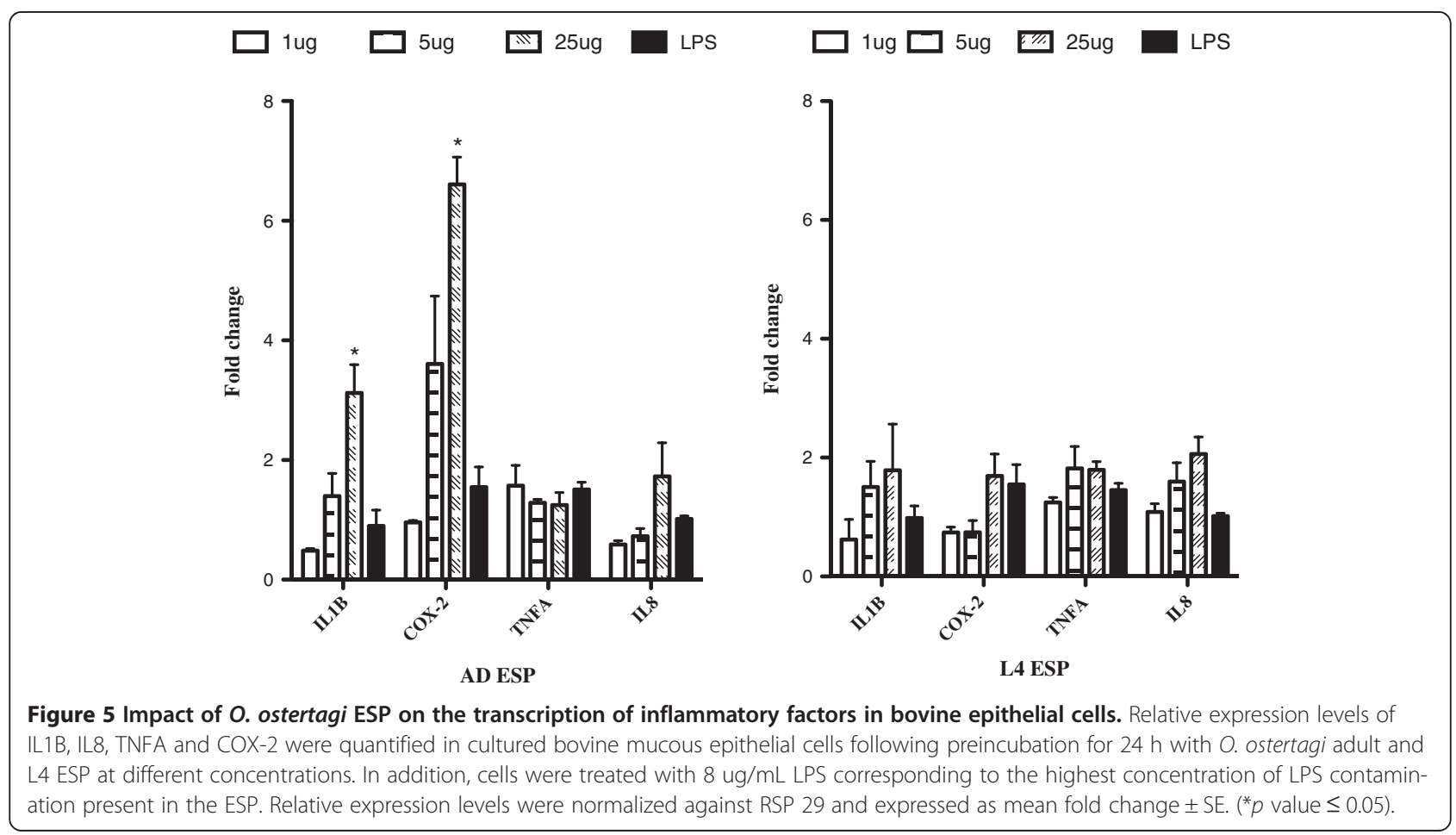


Furthermore, previous studies conducted in mice showed that overexpression of IL1B and PGE2, which is a metabolic product of $\mathrm{COX}-2$, causes an increase of gastric epithelial cell proliferation $[15,23]$. On the contrary, it is also possible that an increase of gastrin secretion reported in several studies [30,31] could play a key role in triggering the observed hyperplastic changes by regulating the pathways discussed above. For example, it has been shown that INS-GAS transgenic mice overexpressing gastrin have a thickened hyperplastic mucosa [32].

In addition to the impact of gastrin on epithelial cell proliferation, the hypergastrinemia has also been associated with a marked decrease of parietal cell numbers in INS-GAS mice [32]. This might explain the parietal cell loss and subsequently the reduction of acid secretion after infection with $O$. ostertagi for a long period of time. Previous studies showed that ostertagiosis results in a marked reduction of abomasal acid production [4,33-35], associated with the emergence of adult worms from the fundic mucosa [4]. Several reports showed that a similar effect on acid secretion was observed only a few hours after the transplantation of adult T. circumcincta and $O$. ostertagi in the abomasum of naïve animals [34,36]. Furthermore, transplantation of $T$. circumcincta adult worms, which were prevented from mucosal contact, leads to reduced abomasal acid output also within a few hours [8]. Our study shows that the emergence of adult worms in the abomasum was not accompanied by a significant disappearance of parietal cells, suggesting that the rapid increase of the gastric $\mathrm{pH}$, which is associated with the emergence of adult abomasal nematodes, is more likely due to the inhibition of parietal cell function rather than a reduction in parietal cell numbers.

Our data show that ESP produced by adult O. ostertagi could be implicated in the inhibition of gastric acid secretion. The incubation of parietal cells with adult ESP resulted in the inhibition of their activity. Furthermore, heat treatment of adult ESP resulted in the abolishment of the inhibitory effect, suggesting that the impairment of acid secretion is mediated by worm secreted/excreted protein requiring an adequate folding to mediate its effect. Previously, Merkelbach et al. showed that adult ESP of $H$. contortus inhibited acid production in histamine stimulated rabbit gastric glands. The inhibitory effect was attributed to the presence of ammonia in adult ESP [37]. However, the authors did not investigate the impact of high molecular weight products on acid secretion. Our data also show that exposure of parietal cells to adult ESP for a short period of time did not impair the histaminergic stimulation of parietal cells. A direct inactivation of the histamine receptor with O. ostertagi ESP through a competitive antagonism would have resulted in a rapid inhibition of acid secretion. Therefore, the observed inhibitory effect of adult ESP is probably not mediated by a direct interaction of ESP with the histamine receptor. Previous studies showed that the activation of the histamine receptor in parietal cells results successively in increased levels of cytoplasmic cAMP, activation of protein kinase A (PKA) and the reorganization of the cytoskeleton, leading to the formation of secretory canaliculi. We show that adult ESP was able to reduce acid secretion in cAMP-stimulated parietal cells, suggesting that the inhibition of parietal cells by $O$. ostertagi ESP was not triggered at the cAMP generation level by the histamine receptor. Therefore, the molecular site of parietal cell inhibition by adult ESP should be at the level of the downstream effectors involved in the formation of secretory vacuoles.

The marked increase in $I L 1 B$ and $C O X-2$ expression associated with the presence of the adult stage worms might also explain the rapid increase of abomasal $\mathrm{pH}$. Our data show that adult ESP induced the production of IL1B and COX-2 in epithelial cells, suggesting that adult ESP might inhibit parietal cell activity by inducing inflammatory cytokine production in mucous epithelial cells. However, whether mucous epithelial cells in vivo are exposed to similar ESP concentrations as used in the in vitro experiment remains unknown. Previous reports showed that the inflammatory factors such as $I L 1 B$, TNFA and PGE2 are able to alter parietal cell function $[13,16] . I L 1 B$ and TNFA have been shown to inhibit both cholinergic and histaminergic stimulated rabbit parietal cells, while PGE2 can inhibit histamine-activated parietal cells through the inhibition of cAMP generation by Adenylate Cyclase following histamine stimulation. Interestingly, our data show that the mechanism of parietal cell inhibition by adult ESP differs from those described above for the inflammatory factors, suggesting that both pathways can be active in the inhibition of parietal cell activity during an $O$. ostertagi infection.

In the present study we used rabbit parietal cells as a model to investigate the impact of O. ostertagi ESP on gastric acid secretion. This was motivated by the fact that, unlike cultured rabbit parietal cells, bovine parietal cells are not responsive to histamine and carbachol stimulations. Previous attempts to obtain responsive gastric glands from sheep and cows were also not successful $[37,38]$. Dispersed bovine gastric glands are insensitive to histamine, however they are stimulated by dbcAMP treatment [38]. In our hands, cultured bovine parietal cells did not show any morphological feature of activation following histamine and carbachol stimulation as well as dbcAMP treatment (data not shown). In the same manner Merkelbach et al. showed that sheep gastric glands were insensitive to histamine stimulation and subsequently they were not suitable to investigate the 
impact of the worm chemicals on acid production [37]. Despite the unresponsiveness of ruminant parietal cells in vitro to the common secretagogues, subcutaneous injection of histamine and carbachol induces a decrease in $\mathrm{pH}$ in sheep abomasum. Furthermore, the administration of cimetidine and atropine, which are respectively antagonists of histamine and carbachol, blocks the acid secretion in sheep [35]. This suggests that similarly to monogastric species, the acid secretion is mediated by histamine and carbachol stimulation in ruminants. The absence of a bovine parietal cell response in vitro might be due to the inadequacy of the isolation and culture protocol for ruminant species.

In conclusion, this study shows that adult $O$. ostertagi is responsible for marked mucosal cell hyperplasia associated with alteration of several signaling pathways involved in the maintenance of gastric epithelial cell homeostasis. Parietal cell numbers were only decreasing after prolonged infection but their function can be inhibited early during primary infection by adult worm ESP. Furthermore, our data show that the mucosal cell hyperplasia and the impairment of parietal cell function could be triggered by the upregulation of inflammatory factors which are in turn partly induced by adult ESP.

\section{Additional files}

Additional file 1: Table S1. List of primers used for qRT-PCR analysis. Additional file 1 presents the complete list of Genes used in the GRT-PCR assay, indicating GeneBank accession number, primer sequences and melting temperatures (Tm).

Additional file 2: Table S2. Postmortem worm counts. Additional file 2 shows the infection doses given to the different experimental groups, the average worm counts recovered at necropsy from the abomasa and the percentage of adult worms.

\section{Competing interests}

The authors declare that they have no competing interests.

\section{Authors' contributions}

BM, MR, SVC, BG, JV, EC and PG conceived and designed the experiments. BM and FVM performed the experiments. WVB and KC participated in the staining work. BM and FVM analyzed the data and performed the statistical analysis. BM drafted the paper and EC, SVC and PG modified and refined it. All authors read and approved the final manuscript.

\section{Acknowledgements}

This research was funded by the Concerted Research Actions of Ghent University (GOA)

\footnotetext{
Author details

'Department of Virology, Parasitology and Immunology, Faculty of Veterinary Medicine, Ghent University, Salisburylaan 133, 9820 Merelbeke, Belgium. ${ }^{2}$ Department of Pathology, Bacteriology and Avian Diseases, Faculty of Veterinary Medicine, Ghent University, Salisburylaan 133, 9820 Merelbeke, Belgium. ${ }^{3}$ Department of Morphology, Faculty of Veterinary Medicine, Ghent University, Salisburylaan 133, 9820 Merelbeke, Belgium.
}

Received: 17 July 2013 Accepted: 29 November 2013

Published: 11 December 2013

\section{References}

1. Murray M, Jennings FW, Armour J: Bovine ostertagiasis: structure, function and mode of differentiation of the bovine gastric mucosa and kinetics of the worm loss. Res Vet Sci 1970, 11:417-427.

2. Karam SM, Straiton T, Hassan WM, Leblond CP: Defining epithelial cell progenitors in the human oxyntic mucosa. Stem Cells 2003, 21:322-336.

3. Katoh M: Dysregulation of stem cell signaling network due to germline mutation, SNP, Helicobacter pylori infection, epigenetic change and genetic alteration in gastric cancer. Cancer Biol Ther 2007, 6:832-839.

4. Jennings FW, Armour J, Lawson DD, Roberts R: Experimental Ostertagia ostertagi infections in calves: studies with abomasal cannulas. Am J Vet Res 1966, 27:1249-1257.

5. Scott I, Hodgkinson SM, Khalaf S, Lawton DE, Collett MG, Reynolds GW Pomroy WE, Simpson HV: Infection of sheep with adult and larval Ostertagia circumcincta: abomasal morphology. Int J Parasitol 1998, 28:1383-1392.

6. Scott I, Khalaf S, Simcock DC, Knight CG, Reynolds GW, Pomroy WE, Simpson HV: A sequential study of the pathology associated with the infection of sheep with adult and larval Ostertagia circumcincta. Vet Parasitol 2000, 89:79-94.

7. Huby F, Hoste H, Mallet S, Fournel S, Nano JL: Effects of the excretory/ secretory products of six nematode species, parasites of the digestive tract, on the proliferation of HT29-D4 and HGT-1 cell lines. Epithelial Cell Biol 1995, 4:156-162.

8. Simpson HV, Simpson BH, Simcock DC, Reynolds GW, Pomroy WE: Abomasal secretion in sheep receiving adult Ostertagia circumcincta that are prevented from contact with the mucosa. N Z Vet J 1999, 47:20-24.

9. De Bock M, Decostere A, Hellemans A, Haesebrouck F, Ducatelle R: Helicobacter felis and Helicobacter bizzozeronii induce gastric parietal cell loss in Mongolian gerbils. Microbes Infect 2006, 8:503-510.

10. Maratea KA, Miller MA: Abomasal coccidiosis associated with proliferative abomasitis in a sheep. J Vet Diagn Invest 2007, 19:118-121.

11. Masuno K, Yanai T, Hirata A, Yonemaru K, Sakai H, Satoh M, Masegi T, Nakai Y: Morphological and immunohistochemical features of Cryptosporidium andersoni in cattle. Vet Pathol 2006, 43:202-207.

12. Xiao SY, Hart J: Marked gastric foveolar hyperplasia associated with active cytomegalovirus infection. Am J Gastroenterol 2001, 96:223-226.

13. Beales IL, Calam J: Interleukin 1 beta and tumour necrosis factor alpha inhibit acid secretion in cultured rabbit parietal cells by multiple pathways. Gut 1998, 42:227-234.

14. Oshima H, Oshima M: Mouse models of gastric tumors: Wnt activation and PGE2 induction. Pathol Int 2010, 60:599-607.

15. Tu S, Bhagat G, Cui G, Takaishi S, Kurt-Jones EA, Rickman B, Betz KS, Penz-Oesterreicher M, Bjorkdahl O, Fox JG, Wang TC: Overexpression of interleukin-1beta induces gastric inflammation and cancer and mobilizes myeloid-derived suppressor cells in mice. Cancer Cell 2008, 14:408-419.

16. Zucker KA, Zdon MJ, Adrian TE, Ballantyne GH, Modlin IM: Prostaglandin inhibition of acid is camp dependent. J Surg Res 1987, 42:513-520.

17. Mihi B, Rinaldi M, Geldhof P: Effect of an Ostertagia ostertagi infection on the transcriptional stability of housekeeping genes in the bovine abomasum. Vet Parasitol 2011, 181:354-359.

18. Geldhof P, Claerebout E, Knox DP, Agneessens J, Vercruysse J: Proteinases released in vitro by the parasitic stages of the bovine abomasal nematode Ostertagia ostertagi. Parasitology 2000, 121:639-647.

19. Geldhof $P$, Claerebout E, Knox D, Vercauteren I, Looszova A, Vercruysse J: Vaccination of calves against Ostertagia ostertagi with cysteine proteinase enriched protein fractions. Parasite Immunol 2002, 24:263-270

20. Hoorens P, Rinaldi M, Mihi B, Dreesen L, Grit G, Meeusen E, Li RW, Geldhof $P$ : Galectin-11 induction in the gastrointestinal tract of cattle following nematode and protozoan infections. Parasite Immunol 2011, 33:669-678.

21. Agnew BJ, Duman JG, Watson CL, Coling DE, Forte JG: Cytological transformations associated with parietal cell stimulation: critical steps in the activation cascade. J Cell Sci 1999, 112:2639-2646.

22. Mangeat P, Gusdinar T, Sahuquet A, Hanzel DK, Forte JG, Magous R: Acidsecretion and membrane reorganization in single gastric parietal-cell in primary culture. Biol Cell 1990, 69:223-232.

23. Oshima H, Matsunaga A, Fujimura T, Tsukamoto T, Taketo MM, Oshima M: Carcinogenesis in mouse stomach by simultaneous activation of the Wnt signaling and prostaglandin E-2 pathway. Gastroenterology 2006, 131:1086-1095. 
24. Shin M, Noji S, Neubuser A, Yasugi S: FGF10 is required for cell proliferation and gland formation in the stomach epithelium of the chicken embryo. Dev Biol 2006, 294:11-23.

25. Kim TH, Shivdasani RA: Notch signaling in stomach epithelial stem cell homeostasis. J Exp Med 2011, 208:677-688.

26. Jensen J, Pedersen EE, Galante P, Hald J, Heller RS, Ishibashi M, Kageyama R, Guillemot F, Serup P, Madsen OD: Control of endodermal endocrine development by Hes-1. Nat Genet 2000, 24:36-44.

27. Joh T, Kataoka H, Tanida S, Watanabe K, Ohshima T, Sasaki M, Nakao H, Ohhara H, Higashiyama S, Itoh M: Helicobacter pylori-stimulated interleukin-8 (IL-8) promotes cell proliferation through transactivation of epidermal growth factor receptor (EGFR) by disintegrin and metalloproteinase (ADAM) activation. Dig Dis Sci 2005, 50:2081-2089.

28. Guo T, Qian JM, Zhao YQ, Li XB, Zhang JZ: Effects of IL-1 beta on the proliferation and apoptosis of gastric epithelial cells and acid secretion from isolated rabbit parietal cells. Mol Med Rep 2013, 7:299-305.

29. Beales IL: Effect of interlukin-1 beta on proliferation of gastric epithelial cells in culture. BMC Gastroenterol 2002, 2:7.

30. Hilderson H, Dorny P, Berghen P, Vercruysse J, Fransen J, Braem L: Gastrin and pepsinogen changes during an Ostertagia ostertagi challenge infection in calves. Zentralb/ Veterinarmed B 1991, 38:25-32.

31. Purewal A, Fox MT, Shivalkar P, Carroll AP, Uche UE, Vaillant C, Watkinson A: Effects of Ostertagia ostertagi on gastrin gene expression and gastrinrelated responses in the calf. J Physiol 1997, 498:809-816.

32. Wang TC, Dangler CA, Chen D, Goldenring JR, Koh T, Raychowdhury R, Coffey RJ, Ito S, Varro A, Dockray GJ, Fox JG: Synergistic interaction between hypergastrinemia and Helicobacter infection in a mouse model of gastric cancer. Gastroenterology 2000, 118:36-47.

33. Anderson N, Armour J, Eadie MR, Jarrett WFH, Jennings FW, Ritchie JSD, Urquhart GM: Experimental Ostertagia ostertagi infections in calves: results of single infections with five graded dose levels of larvae. Am J Vet Res 1966, 27:1259-1265.

34. Lawton DE, Reynolds GW, Hodgkinson SM, Pomroy WE, Simpson HV Infection of sheep with adult and larval Ostertagia circumcincta: effects on abomasal pH and serum gastrin and pepsinogen. Int J Parasitol 1996, 26:1063-1074.

35. Hertzberg H, Guscetti F, Lischer C, Kohler L, Neiger R, Eckert J: Evidence for a parasite-mediated inhibition of abomasal acid secretion in sheep infected with Ostertagia leptospicularis. Vet J 2000, 159:238-251.

36. McKellar Q, Duncan JL, Armour J, McWilliam P: Response to transplanted adult Ostertagia ostertagi in calves. Res Vet Sci 1986, 40:367-371.

37. Merkelbach P, Scott I, Khalaf S, Simpson HV: Excretory/secretory products of Haemonchus contortus inhibit aminopyrine accumulation by rabbit gastric glands in vitro. Vet Parasitol 2002, 104:217-228.

38. Mckellar QA, Mostofa M, Eckersall PD: Effect of Ostertagia ostertagi secretions and various putative secretagogues and inhibitors on aminopyrine accumulation in dispersed bovine abomasal gland-cells. Res Vet Sci 1990, 49:323-326.

doi:10.1186/1297-9716-44-121

Cite this article as: Mihi et al: Analysis of cell hyperplasia and parietal cell dysfunction induced by Ostertagia ostertagi infection. Veterinary Research 2013 44:121.

\section{Submit your next manuscript to BioMed Central and take full advantage of:}

- Convenient online submission

- Thorough peer review

- No space constraints or color figure charges

- Immediate publication on acceptance

- Inclusion in PubMed, CAS, Scopus and Google Scholar

- Research which is freely available for redistribution
C Biomed Central 